\title{
Impact of fatty degeneration on the functional outcomes of 38 patients undergoing surgical repair of gluteal tendon tears
}

\author{
Alexander Maslaris ${ }^{1,2,3} \cdot$ Thomas P. Vail $^{1} \cdot$ Alan L. Zhang ${ }^{1} \cdot$ Rina Patel $^{4} \cdot$ Stefano A. Bini ${ }^{1}$
}

Received: 20 August 2020 / Accepted: 15 October 2020 / Published online: 2 March 2021

(c) The Author(s) 2021, corrected publication 2021

\begin{abstract}
Background Gluteal tendon tears (GTT) can cause pain and weakness of the hip. We analyze the impact of gluteal muscle fatty degeneration, atrophy and tear morphology on clinical outcomes of surgical repair.

Methods All sequential patients receiving surgical repair of GTTs via anchor sutures between 1/2015 and 11/2018 were retrospectively identified. MRIs were reviewed by a radiologist for tendon retraction, muscle atrophy and tear size. The Goutallier-Fuchs Classification (GFC) was used to quantify fatty degeneration as $<2^{\circ}$ or $\geq 2^{\circ}$. Demographic and clinical variables were abstracted from the electronic records. The surveys HHS Section 1 and HOOS Jr. were obtained at last follow-up. The Pearson correlation and one-way ANOVA tests served for statistical analysis of clinical variance.

Results 38 patients were identified, $29(76.3 \%)$ were female. The average age was 67. Of the $11(28.9 \%)$ patients with a prior hip arthroplasty $87.5 \%$ of primary THAs had a direct lateral approach. 29 (76.3\%) patients were treated open and $9(23.7 \%)$ arthroscopically. At an average follow-up of 20.9 months, patients reported a significant improvement in pain (97\%), analgesic use (85.7\%), limp (52.6\%) and abduction strength (54.2\%) (all: $P \leq 0.01)$. GFC $\geq 2^{\circ}$ were associated with significantly worse outcomes in terms of limp (0.19/3 vs. $1.2 / 3, P=0.05)$, HHS-S1 (58.19 vs. $71.68, P=0.04)$ and complication rates (37.5\% vs. $0 \%, P=0.02)$. There was a strong correlation between tear retraction $(P=0.005)$, tear size $(P=0.009)$ and muscle atrophy $(P=0.001)$ with $\mathrm{GFC} \geq 2^{\circ}$ but not with clinical outcomes. GFC $\geq 2^{\circ}$ was strongly related to lateral THA exposures $(P<0.001)$. Surgical approach had no impact on clinical outcomes.

Conclusion While fatty degeneration can negatively impact functional outcomes, pain relief is reliably achieved. Tear morphology and muscle atrophy did not correlate with outcomes in this patient cohort. Patients should be counseled to expect a residual limp after surgery if they have GFC $\geq 2^{\circ}$ on MRI.
\end{abstract}

Keywords Gluteal tendon rupture · Gluteus medius et minimus tear · Gluteal tendon repair · Gluteal tendon refixation techniques $\cdot$ Fatty degeneration of gluteal muscles

\section{Introduction}

Gluteal tendon tears (GTT) are often unrecognized and treated inadequately [1]. Depending on their severity and etiology, symptoms may vary from a sole lateral hip pain to a persistent abductor insufficiency of the hip. Structural parameters of GTT such as tear size, retraction of the torn tendon [2-4], fatty degeneration and atrophy of the injured muscle [3, 5-7] may impact the clinical outcomes of surgical

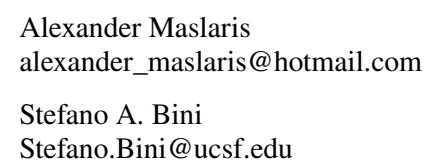

Extended author information available on the last page of the article treatment. Demographic aspects of the individual patient like age [8,9], gender [10], bone mineral density (BMD) $[11,12]$ and body mass index (BMI) as well as the presence of a preexisting total hip arthroplasty (THA) and the number of previous revision THAs (RHA) [13] pose potential risk factors for the success of the initiated therapy. In particular, postsurgical GTTs are associated with the direct lateral THA approach $[14,15]$ or even the anterolateral THA approach [16].

The surgical treatment of GTT includes the reattachment of the torn tendon using sutures/suture anchors in single or double-rows with or without fixation via various augmentation techniques depending on the severity of the GTT and the soft tissue quality $[2,11,17-23]$. Some authors have recommended muscle transfer techniques as the only solution 
in cases of non-reconstructable GTTs with severe soft tissue damage [24-33].

Available evidence suggests that surgical repair of GTT with either open $[2,5,17,18,20-22,34-45]$ or endoscopic techniques [6, 46-53] can lead to very good to excellent results with a significant improvement in pain. However, risk factors such as fatty degeneration (FD), muscle atrophy (MA) and tear morphology (TM) may impact negatively the surgical results. Thus, more complex tears and patients with higher comorbidities tend to show less favorable outcomes and needed commonly to be treated in an open fashion [54].

Related literature up to now suffers from inhomogeneity and small sample sizes making reliable conclusions and developing transparent treatment algorithms impossible. Thus, little is known about the comparative impact of FD, MA and TM on the postoperative outcomes between open (OGR) and endoscopic gluteal repair (EGR) in minimizing pain and restoring function.

The aim of the study is to analyze the impact of fatty degeneration and the other risk factors on the mid-term results in a large cohort of patients who underwent either EGR or OGR of GTTs via suture anchors.

\section{Materials and methods}

Approval from the local Institutional Review Boards was granted. A retrospective single-center cohort study from a university hospital was conducted. All sequential patients receiving surgical repair of GTTs via anchor sutures between $1 / 2015$ and 11/2018 were identified and retrospectively recruited for the study. Treatment was divided in: (1) EGR, (2) primary OGR (pOGR) and (3) revision total hip arthroplasties with OGR (rOGR).

All patients who were included in the study presented with persistent lateral hip pain with or without signs of hip abductor insufficiency and a positive magnetic resonance imaging (MRI) for GTT prior to surgery. Exclusion criteria were septic surgeries, active tumors or known neurological diseases that affected the hip, no preoperative MRI or inability to assess due to massive hardware artifacts, patients who refused to participate to the study and finally cases with missing or inconsistent documentation.

Demographic and clinical variables were abstracted from the electronic record using an institutional database. Age, gender, BMI and comorbidity level, as defined by the America Society of Anesthesiologist (ASA), were collected.

The GTT etiology was divided into (1) degenerative, (2) posttraumatic or (3) postoperative (prior THA) causes.

Preoperative x-rays were assessed to measure the femoral offset and look for any malposition or instability of preexisting implants on the hip or lumbar spine.
The preoperative MRI was used to evaluate the fatty infiltration and atrophy of the gluteal muscles and to analyze the complexity of the GTTs.

The fatty infiltration of the gluteal muscles was grouped based on the Goutallier-Fuchs classification (GFC) in: $0=$ normal muscle, $1=$ muscles with some fatty streaks, $2=$ muscles with moderate fatty streaks (more muscle than fat), $3=$ muscles with severe fatty streaks (equal amounts of fat and muscle), and $4=$ muscles with more fat than muscle [55-57]. Based on recent studies [3, 5], GFC was further divided into two clinically relevant main groups, namely into below $\left(\mathrm{GFC}<2^{\circ}\right)$ and above grade $2\left(\mathrm{GFC} \geq 2^{\circ}\right)$. The assessment included the gluteus minimus (Gmin) and three distinct parts of the gluteus medius muscle (Gmed): the anterior, mid and posterior portion of Gmed (Fig. 1). This technique is described by Thaunat et al. [6]. According to that study, gluteus medius and minimus muscles were evaluated on the axial $\mathrm{T} 1$ sequences without fat saturation on the first axial slice inferior to the sacroiliac joint.

Muscle atrophy of the hip abductors was defined as the reduction of the size of its components by $\geq 25 \%$ then that of the contralateral side [58].

The gluteus medius and minimus tendons were assessed separately for presence or absence of tear. All available fluidsensitive sequences (STIR or T2 fat saturation) were used

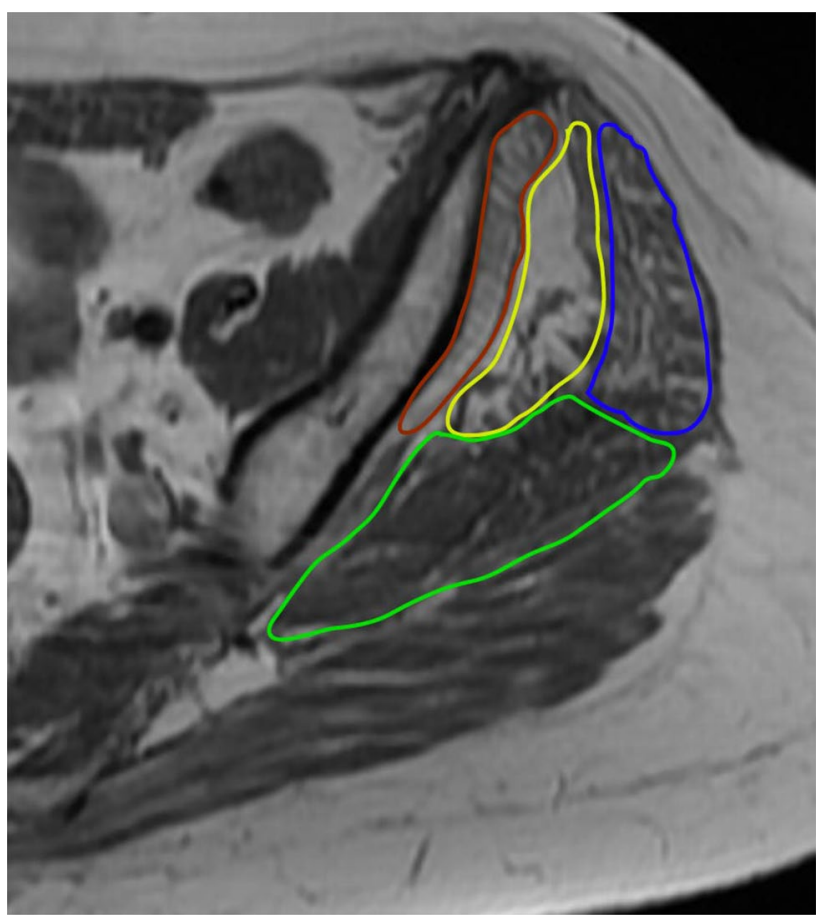

Fig. 1 An axial T1 sequence of an MRI illustrating the Gmin and the three district parts of Gmed, that were included in the assessment of fatty degeneration as described by Thaunat [6]: Gmin (rot), anterior portion (blue), mid portion (yellow) and posterior portion of Gmed (green) 
to evaluate and characterize the tear. The tears were characterized as full-thickness lesions (FT) or partial-thickness lesions (PT), which were further differentiated into lateral bursal-side (LPT) or medial joint-side partial tears (MPT). The length of tendon retraction was measured from their attachment on the greater tuberosity. The anteroposterior width of the tear was also measured (Fig. 2a-d). Any evidence of bursitis was classified in $0=$ none, $1=$ mild, $2=$ moderate, or $3=$ severe as described by Chi et al. [59]. All MRI measurements mentioned above were performed by an experienced musculoskeletal radiologist.

All patients included in the study were contacted postoperatively via e-mail or phone and invited to an anonymous survey to evaluate the postoperative results. For this purpose, following patient-reported outcome measures (PROMs) were used: The Hip disability and Osteoarthritis Outcome Score Junior (HOOS Jr.) [60], the questionnaire of the first section of Harris Hip Score (HHS-S1) [61], that concerns pain and function features, and the Visual Analog Scale of pain (VAS). Furthermore, the amount and type of analgesics been taken at the time of the survey due to still existing hip pain was verified.

Following postoperative outcome values were analyzed:
2. Limp severity based on the HHS protocol, classified as: $0=$ non, $1=$ mild, $2=$ moderate, $3=$ severe and $4=$ extreme

3. Hip abduction strength, according to the Medical Research Council Score (MRC-Score) [62]

4. Number of non-opioid analgesics including nonsteroidal anti-inflammatory drugs (NSAIDs) and analgesic adjuvants (Acetaminophen, Ibuprofen, Naproxen, Meloxican, Ketorolac, Celecoxib, Gabapentin, Temazepam, Metaxalone, Baclofen)

5. Number of opioid drugs (Hydrocodone, Oxycodone, Tramadol) taken at the time of last follow-up.

The software IBM SPSS (Version 25.0) was used to perform statistical analysis. The Pearson correlation test was used to assess possible correlations between potential risk factors and outcomes. The two-tailed paired T-test was used to compare pairwise the postoperative results with the preoperative findings. The one-way analysis of variance (ANOVA) and the least significant difference (LSD) tests were performed for single or multiple intergroup comparisons between different patient subgroups.

1. Pain intensity, according to VAS scale

Fig. 2 a-d Preoperative MRI revealing a GTT on the left side. In the axial views a the right healthy side and $\mathbf{b}$ the anteroposterior detachment on the lateral aspect of trochanter. In the coronal plane $\mathbf{c}$ and $\mathbf{d}$ the retraction of the torn gluteal muscle compared to the healthy contralateral hip
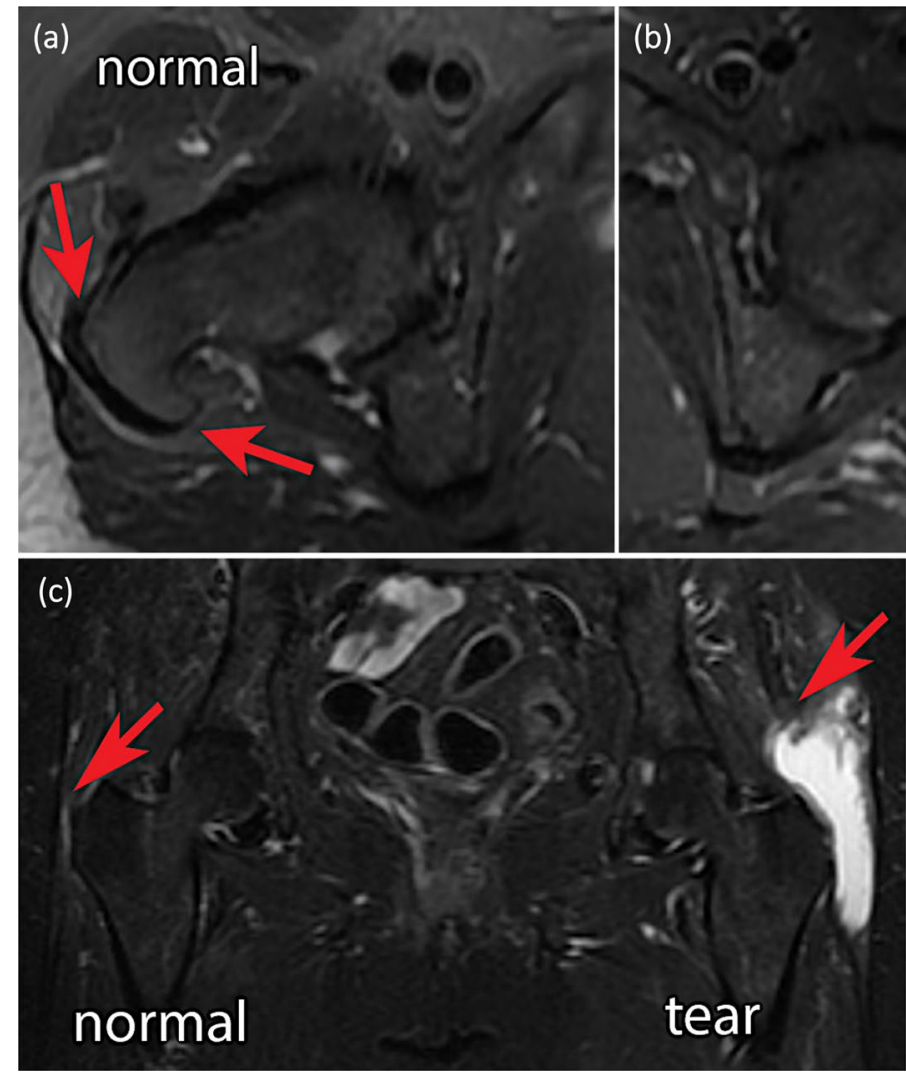
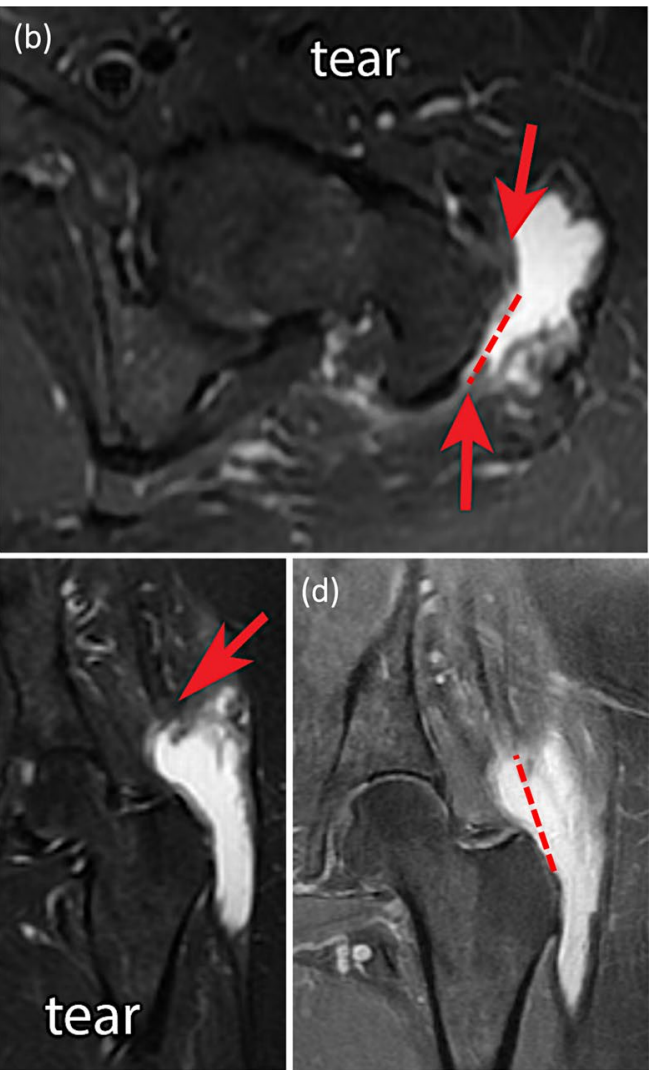


\section{Results}

From the 38 patients, who met inclusion criteria, 29 (76.3\%) were females and the average age was 66.7. Eleven patients (29\%) had a prior hip replacement, $87.5 \%$ of which were performed via a direct lateral approach.

$29(76.3 \%)$ patients were treated open and $9(23.7 \%)$ endoscopically. In all cases, suture anchors were used for the repair of the GTTs (in 76\% of cases: Suture Anchor Corkscrew $5.0 \mathrm{~mm}$ with \#2 Fiberwire, Arthrex, Naples, FL, USA; in 16\%: Nanotack Suture Anchor System with Iconix \#2, Stryker, Kalamazoo, MI, USA; in 5\%: PEEK Zip Suture Anchor 5.5 mm Stryker, Kalamazoo, MI, USA; in 3\%: a GII Quickanchor with Orthocord, DePuy Mitek, Raynham, MA, USA). In two cases with advanced fatty degeneration, additional augmentation via nonabsorbable synthetic Mersilene mesh (GFC 2.7 ${ }^{\circ}$ ) and Achilles tendon allograft fixed with $3.5 \mathrm{~mm}$ cortical screws (GFC $2.6^{\circ}$ ) were required.

At an average follow-up of 21 months, a significant overall improvement in pain (97\%), limp (52.6\%), and abduction strength $(54.2 \%)$ as well as in reduction of non-opioid analgesic use $(85.7 \%)$ and opioid use $(81.3 \%)$ was noticed independent of surgical approach (all with $P \leq 0.01$ ) (Fig. 3).

The differences between each GFC groups are summarized as follows (Table 1).

Whilst GFC $<2^{\circ}$ had no negative impact on clinical outcomes, GFC $\geq 2^{\circ}$ was associated with significantly worse outcomes with respect to a patient's reported limp (average: $0.19 / 3$ vs. $1.2 / 3, P=0.05$ ) (Fig. 4), HHS-S1 scores (58.19 vs. $71.68, P=0.04)$ and complication rates $(37.5 \%$ vs. $0 \%, P=0.02$ ) (Tables 2 and 3 ). Though GTT retraction $(P=0.005)$, tear size $(P=0.009)$ and significant association with the postoperative clinical outcome values. Cases with GFC $\geq 2^{\circ}$ were strongly correlated with THA lateral exposures $(P<0.001)$ and the need to use more anchors for the GTT repair $(P=0.004)$. The severity of trochanteric bursitis

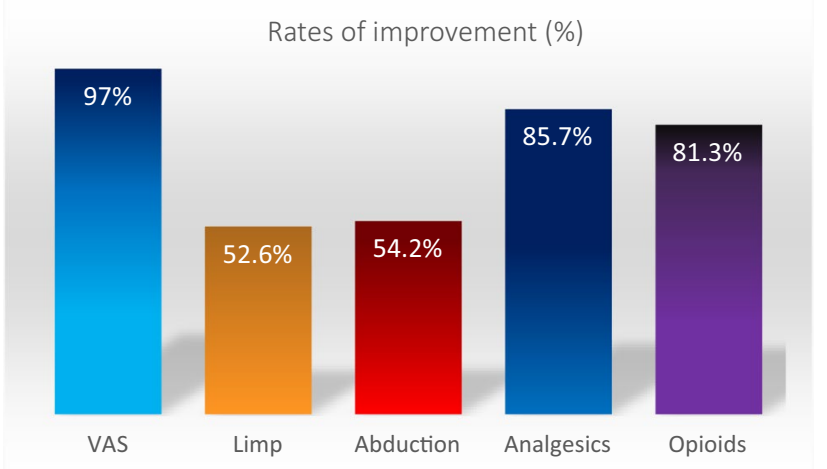

Fig. 3 Percentage of the overall cases with verified improvement of the main outcome objectives after surgical treatment of GTT on pre-operative MRI was significantly associated with both the fatty degeneration and atrophy of the injured gluteal muscles ( $P=0.02$ and $P=0.008$, respectively). $83.8 \%$ of all GTT revealed a mean bursitis scale of $1.54 \pm 1.0^{\circ}$.

From the 28 preoperative MRIs with possible evaluation of muscle atrophy, $24(85.7 \%)$ cases revealed a MA on both the Gmed and Gmin whereas in 18 (64.3\%) of the cases only the Gmed was affected.

Muscle atrophy was associated with the etiology of a GTT $(P=0.039)$, being evidenced more often in the rOGR group. Atrophy was also correlated with the Gmed retraction $(P=0.035)$ and tear size $(P=0.037)$. GTTs with a $\mathrm{MA} \geq 25 \%$ showed significantly higher levels of Gmed retraction ( $0 \mathrm{~mm}$ vs. $15.3 \pm 1.9 \mathrm{~mm}, P=0.01)$ and fatty degeneration $(1.48 \pm 0.9$ vs. $2.6 \pm 0.8, P<0.001)$ and were found more often in cases with preexisting THA (50\% vs. $10 \%, P=0.02$ ) when compared to the GTT group without MA (Table 4). However, MA did not have any significant impact on clinical outcomes and functional PROMs at the last postoperative follow-up.

\section{Discussion}

Independent of the operative approach used to treat gluteal tendon tears, fatty degeneration of gluteal muscles GFC $\geq 2^{\circ}$ seems to be associated with significantly worst functional outcomes after surgical repair. GTT muscle atrophy and retraction did not reveal any association to the postoperative results in our patient cohort. Nevertheless, this should be considered cautiously since it might be due to the small subgroup sizes that met inclusion criteria within the current study design. Finally, statistically significant improvement of all main outcome measures (VAS, limp, abduction, analgesics, opioids) were achieved in all cases of GTT after surgical treatment (Tables 1 and 2) suggesting that even patients with advanced fatty degeneration may benefit from direct surgical repair.

The subgroup analysis showed detailed impact of fatty degeneration. GFC $\geq 2^{\circ}$ was associated with considerably inferior outcomes in the functional section S1 of HHS and limp after GTT surgical repair when compared to GFC $<2^{\circ}$ ( $P=0.04$ and $P=0.025$, respectively). Furthermore, complication rates were significantly higher in the GFC $\geq 2^{\circ}$ group ( $37.5 \%$ vs. $0 \%, P=0.02$ ). However, whilst it is known that fatty degeneration has a negative impact on postoperative functional outcomes $[3,6,7]$, our study suggests that pain relief can be reliably accomplished after surgical treatment of GTTs regardless of the degree of GFC. Thus, our results align with the available literature, suggesting that surgical reattachment of GTT is an effective treatment option for persistent lateral hip pain [44, 63]. 
Table 1 Demographics, findings and outcomes in relation to fatty degeneration of gluteal muscle according to Goutallier-Fuchs Classification (values in means + standard deviation)

\begin{tabular}{|c|c|c|c|c|c|}
\hline GFC & $0^{\circ}$ & $1^{\circ}$ & $2^{\circ}$ & $3^{\circ}$ & All \\
\hline $\mathrm{Nr}$ & $6(15.8 \%)$ & $16(42.1 \%)$ & $10(26.3 \%)$ & $6(15.8 \%)$ & 38 \\
\hline Age & $64 \pm 12.2$ & $63 \pm 8.6$ & $69,5 \pm 11.3$ & $71,5 \pm 4.6$ & $66.7 \pm 9.9$ \\
\hline Gender (females) & $5(83.3 \%)$ & $13(81.3 \%)$ & $6(60 \%)$ females & $5(83.3 \%)$ & $29(78 \%)$ \\
\hline ASA & $\begin{array}{l}1(16.7 \%) \mathrm{I}^{\circ} \\
3(50 \%) \mathrm{II}^{\circ} \\
2(33.3 \%) \mathrm{III}^{\circ}\end{array}$ & $\begin{array}{l}0(0 \%) \mathrm{I}^{\circ} \\
14(87.5 \%) \mathrm{II}^{\circ} \\
2(12.5 \%) \mathrm{III}^{\circ}\end{array}$ & $\begin{array}{l}1(10 \%) \mathrm{I}^{\circ} \\
7(70 \%) \mathrm{II}^{\circ} \\
2(20 \%) \mathrm{III}^{\circ}\end{array}$ & $\begin{array}{l}1(16.7 \%) \mathrm{I}^{\circ} \\
4(66.7 \%) \mathrm{II}^{\circ} \\
1(16.7 \%) \mathrm{III}^{\circ}\end{array}$ & $\begin{array}{l}3(7.9 \%) \mathrm{I}^{\circ} \\
28(73.7 \%) \mathrm{II}^{\circ} \\
7(18.4 \%) \mathrm{III}^{\circ}\end{array}$ \\
\hline BMI & $28.24 \pm 6.5$ & $27,7 \pm 4.2$ & $30,2 \pm 7.6$ & $27 \pm 5.7$ & 28,33 \\
\hline Etiology & $\begin{array}{l}5(83.3 \%) \text { spontaneous } \\
1(17 \%) \text { posttraumatic }\end{array}$ & $\begin{array}{l}13(81.3 \%) \text { spontaneous } \\
2(12,5 \%) \text { posttraumatic } \\
1(6.3 \%) \text { prior THA }\end{array}$ & $\begin{array}{l}2(20 \%) \text { spontaneous } \\
1(10 \%) \text { posttraumatic } \\
7(70 \%) \text { prior THA } \\
4 \text { primary THA } \\
3 \text { revision THA }\end{array}$ & $\begin{array}{l}2(33.3 \%) \text { spontaneous } \\
1(16.7 \%) \text { posttraumatic } \\
3(50 \%) \text { prior THA }\end{array}$ & $\begin{array}{l}22(57.9 \%) \text { spontaneous } \\
5(13.2 \%) \text { posttraumatic } \\
11(28.9 \%) \text { prior THA }\end{array}$ \\
\hline THA approaches & None & 1/1 LA & $4 / 4 \mathrm{LA}$ & 2/3 LA & $7 / 8(87.5 \%) \mathrm{LA}$ \\
\hline Prior RHA nr & None & None & $\begin{array}{l}2(20 \%) \geq 3 \text { RHA } \\
1(10 \%)<3 \text { RHA }\end{array}$ & none & $\begin{array}{l}3 \text { prior RHA } \\
(1:<3,2: \geq 3 \text { RHAs })\end{array}$ \\
\hline FOS (mm) & $46.5 \pm 1.5$ & $46.8 \pm 6.9$ & $48.2 \pm 4.7$ & $46.6 \pm 6.7$ & $47.1 \pm 5.6$ \\
\hline Injured tendons & $\begin{array}{l}60 \% \text { Gmed } \\
20 \% \text { Gmin } \\
20 \% \text { Gmed \& Gmin }\end{array}$ & $\begin{array}{l}50 \% \text { Gmed } \\
12.5 \% \text { Gmin } \\
31.3 \% \text { Gmed \& Gmin }\end{array}$ & $\begin{array}{l}50 \% \text { Gmed } \\
0 \% \text { Gmin } \\
50 \% \text { Gmed \& Gmin }\end{array}$ & $\begin{array}{l}\text { 16.7\% Gmed } \\
83.3 \% \text { Gmed \& Gmin }\end{array}$ & $\begin{array}{l}1745.6 \% \text { Gmed } \\
38.1 \% \text { Gmin } \\
1643.2 \% \text { Gmed \& Gmin }\end{array}$ \\
\hline Tear type Gmed & $\begin{array}{l}40 \% \text { PT } \\
40 \% \text { FT }\end{array}$ & $\begin{array}{l}31.3 \% \mathrm{PT} \\
43.8 \% \mathrm{FT}\end{array}$ & $\begin{array}{l}40 \% \text { PT } \\
60 \% \text { FT }\end{array}$ & $\begin{array}{l}16.7 \% \mathrm{PT} \\
83.3 \% \mathrm{FT}\end{array}$ & $\begin{array}{l}31.6 \% \mathrm{PT} \\
52.6 \% \mathrm{FT}\end{array}$ \\
\hline Tear type Gmin & $\begin{array}{l}0 \% \text { FT } \\
40 \% \text { PT }\end{array}$ & $\begin{array}{l}31.3 \% \mathrm{PT} \\
18.8 \% \mathrm{FT}\end{array}$ & $\begin{array}{l}30 \% \mathrm{PT} \\
20 \% \mathrm{FT}\end{array}$ & $\begin{array}{l}33.3 \% \mathrm{PT} \\
50 \% \mathrm{FT}\end{array}$ & $\begin{array}{l}26.3 \% \mathrm{PT} \\
21 \% \mathrm{FT}\end{array}$ \\
\hline $\begin{array}{l}\text { Retraction Gmed } \\
\text { in } \mathrm{mm}\end{array}$ & 0 & $5.6 \pm 10.7$ & $18.7 \pm 18.3$ & $20.5 \pm 23.9$ & $8.8 \pm 1.5$ \\
\hline Tear size in $\mathrm{mm}$ & $11.3 \pm 2.3$ & $13.8 \pm 8.9$ & $19 \pm 11.1$ & $30.2 \pm 9.9$ & $15.5 \pm 10.8$ \\
\hline Muscle atrophy $(<25 \%)$ & $50 \%$ & $54 \%$ & $94 \%$ & $100 \%$ & $75 \%$ \\
\hline Bursitis & $1.2 \pm 0.8$ & $1.1 \pm 0.8$ & $1.9 \pm 1.1$ & $2.3 \pm 1.2$ & $1.54 \pm 1.0$ \\
\hline Treatment & $\begin{array}{l}5(83.3 \%) \text { OGR } \\
1(16.7 \%) \text { EGR }\end{array}$ & $\begin{array}{l}9(56.3 \%) \text { OGR: } \\
8(50 \%) \text { pOGR } \\
1(6.3 \%) \text { rOGR } \\
7(43.8 \%) \text { EGR }\end{array}$ & $\begin{array}{l}9(90 \%) \text { OGR: } \\
3(30 \%) \text { pOGR } \\
6(60 \%) \text { rOGR } \\
1(10 \%) \text { EGR }\end{array}$ & $\begin{array}{l}\text { 6(100\%) OGR: } \\
3(50 \%) \text { pOGR } \\
3(50 \%) \text { rOGR }\end{array}$ & $\begin{array}{l}29(76.3 \%) \text { OGR: } \\
19(50 \%) \text { pOGR } \\
10(26.3 \%) \text { rOGR } \\
9(23.7 \%) \text { EGR }\end{array}$ \\
\hline Technique & $\begin{array}{l}10 / 6 \text { anchors } \\
(\text { mean } 1.7+0.5)\end{array}$ & $\begin{array}{l}31 / 16 \text { anchors } \\
(\text { mean } 1.9 \pm 0.9)\end{array}$ & $\begin{array}{l}29 / 10 \text { anchors } \\
(\text { mean } 2.9 \pm 1.1) \\
1 / 10 \text { mesh } \\
1 / 10 \text { Gmax }\end{array}$ & $\begin{array}{l}16 / 6 \text { anchors } \\
(\text { mean } 2.7 \pm 1.2)\end{array}$ & $\begin{array}{l}86 / 38 \text { anchors } \\
(\text { mean } 2.3 \pm 1.0) \\
1 / 38 \text { mesh }\end{array}$ \\
\hline Follow-up (months) & $24.7 \pm 10.5$ & $22.4 \pm 16$ & $19.7 \pm 5.5$ & $15.3 \pm 10.5$ & $20.92 \pm 12.51$ \\
\hline $\begin{array}{l}\text { Abduction } \\
\text { av. Improvement }\end{array}$ & $+0.5 \pm 0.6 / 5$ & $+0.46 \pm 0.9 / 5$ & $+0.4 \pm 0.5 / 5$ & $+0.5 \pm 0.5 / 5$ & $+0.46 \pm 0.7 / 5^{* *}$ \\
\hline $\begin{array}{l}\text { Limp } \\
\text { av. improvement }\end{array}$ & $-1.2 \pm 0.8 / 3$ & $-1.1 \pm 1.1 / 3$ & $0 \pm 1.2 / 3$ & $-0.5 \pm 1.8 / 3$ & $-0.68 \pm 1.3 / 3^{* *}$ \\
\hline $\begin{array}{l}\text { Non-opioid analgesics } \\
\% \text {-reduction }\end{array}$ & $-7 / 8(87.5 \%)$ & $-20 / 25(80 \%)$ & $-16 / 20(80 \%)$ & $-7 / 7(100 \%)$ & $-50 / 60(83.3 \%)^{* *}$ \\
\hline $\begin{array}{l}\text { Opioid } \\
\text { \%-reduction }\end{array}$ & $-2 / 2(100 \%)$ & $-6 / 8(75 \%)$ & $-3 / 4(75 \%)$ & 0.0 & $-11 / 14(78.6 \%)^{* *}$ \\
\hline $\begin{array}{l}\text { VAS } \\
\text { av. improvement }\end{array}$ & $-3.6 / 10$ & $-4.9 / 10$ & $-3.7 / 10$ & $-3.5 / 10$ & $-4.14 / 10 * *$ \\
\hline HOOS Jr & $67 \pm 17.4 / 100$ & $78.7 \pm 14.3 / 100$ & $67 \pm 29.5 / 100$ & $74.6 \pm 18.4 / 100$ & $72.99 \pm 20.6 / 100$ \\
\hline $\begin{array}{l}\text { HHS Sect. } 1 \text { (pain/func- } \\
\text { tion) }\end{array}$ & $65.2 \pm 11.3 / 91$ & $74 \pm 14.4 / 91$ & $58 \pm 21.3 / 91$ & $58.5 \pm 24.3 / 91$ & $65.51 \pm 18.9 / 91$ \\
\hline Complications & None & None & $4 \times$ after rOGR & $2 \times$ after rOGR & $6 / 38(16 \%)$ all after rOGR \\
\hline
\end{tabular}

GFC Goutallier-Fuchs Classification, ASA American Society of Anesthesiologist, BMI Body-Mass-Index, $T H A$ total hip arthroplasty, $L A$ lateral approach, $R H A$ revision hip arthroplasty, $O G R$ open gluteal repair, $p O G R$ primary open gluteal repair, $r O G R$ revision hip arthroplasty with open gluteal repair, EGR endoscopic gluteal repair, GmaxT gluteus maximus transfer, Gmed gluteus medius, Gmin gluteus minimus, $P T$ partial tear, FT full-thickness tear, VAS Visual Analog Scale of pain, HOOS Hip disability and Osteoarthritis Outcome Score Junior, HHS Harris Hip Score

*Significance at the 0.05 level (2-tailed)

**Significance at the 0.01 level (2-tailed) 

tive improvement of the tested outcome variables between $\mathrm{GFC}<2^{\circ}$ and $\mathrm{GFC} \geq 2^{\circ}$
Fig. 4 Means of postopera-

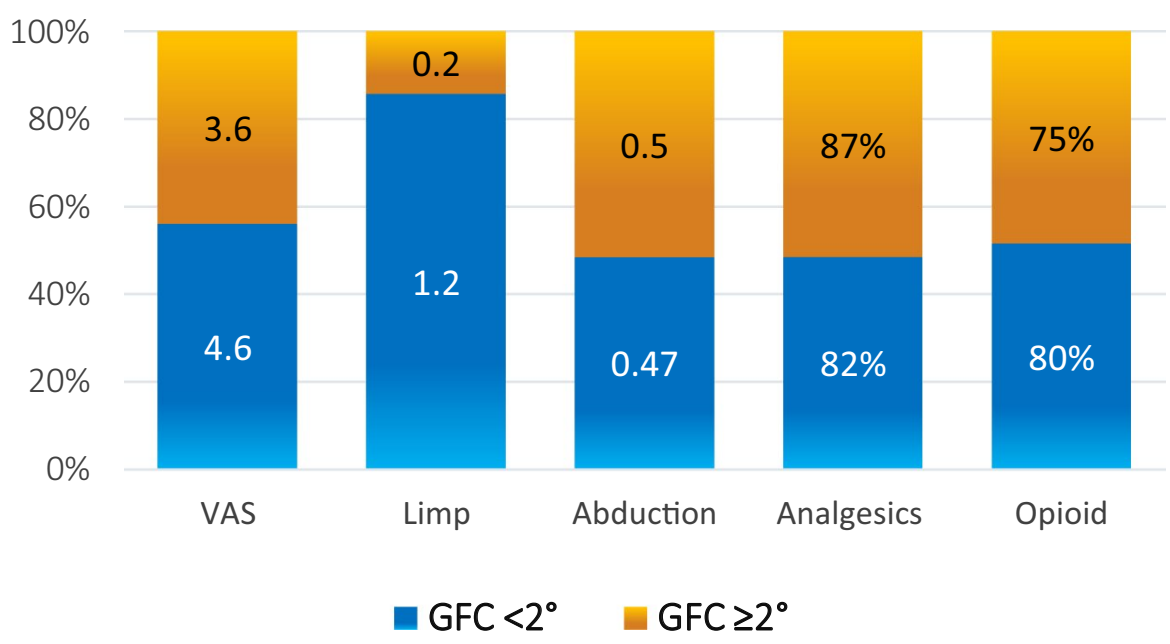

Table 2 Mean differences of pain, limp, abduction strength, $\mathrm{Nr}$. of analgesics and opioids before and after surgery for the groups $\mathrm{GFC}<2^{\circ}$ and $\mathrm{GFC} \geq 2^{\circ}$

\begin{tabular}{|c|c|c|c|c|c|}
\hline & VAS & Limp & Abduction & Analgesics & Opioid \\
\hline $\mathrm{GFC}<2^{\circ}$ & $-4.6 * *$ & $-1.2 * *$ & $+0.47 *$ & $-\mathbf{8 2} \% * *$ & $-80 \% * *$ \\
\hline $\mathrm{GFC} \geq 2^{\circ}$ & $-3.6 * *$ & -0.2 & $+0.5^{*}$ & $-87 \% * *$ & $-75 \%$ \\
\hline All patients & $-4.14 * *$ & $-0.74 * *$ & $+0.46 * *$ & $-85.7 \% * *$ & $78.6 \% * *$ \\
\hline \multicolumn{6}{|c|}{ One-way ANOVA of mean differences comparing outcomes of independent groups } \\
\hline $\mathrm{GFC}<2^{\circ}$ vs. $\geq 2^{\circ}$ & 0.95 & $0.98 *$ & 0.03 & $5 \%$ & $5 \%$ \\
\hline
\end{tabular}

*Significance at the 0.05 level (2-tailed)

**Significance at the 0.01 level (2-tailed)
Current data indicates that endoscopic and open surgical approaches are both equally successful [54]. However, there are some fundamental differences between these two approaches to consider when choosing the proper treatment strategy: endoscopic approach is better suited to smaller tears and tears of the gluteus minimus (cite our prior paper here) and has the benefit of also being able to address articular-side pathologies during the same procedure. Most arthroscopic procedures were used in patients with a low to moderate degree of fatty degeneration $\left(\mathrm{GFC}<2^{\circ}\right)$. There are no data available to our knowledge assessing the efficacy of endoscopic GTT repair in cases with severe GFC. EGR also requires specialized equipment and a considerable learning-curve with the risk of poor anchor placement [64]. Open approaches offer a greater exposure and access to the retracted edge of chronic GTT and therefore provide greater treatment flexibility with more options for fixation including, if required, the use of augmentation or reconstruction techniques in cases with more extended soft tissue damage $[24-33,65,66]$ or palsy of the superior gluteal nerve [16, $67,68]$.

In the current study, MRI findings prior to surgery revealed a strong correlation between fatty degeneration and other abnormal structural properties of the GTTs such as the retraction $(P=0.005)$, tear size $(P=0.009)$, muscle atrophy $(P=0.001)$ and the severity of trochanteric bursitis $(P=0.02)$. There was also a significant difference in the severity of retraction, tear size, muscle atrophy and bursitis of the GTTs between GFC $<2^{\circ}$ and GFC $\geq 2^{\circ}$ (Table 3 ). However, we could not find any significant impact of the above-mentioned variables on the postoperative results after GTT repair. In contrast, previous publications support the importance of tear size and retraction on the success of surgical treatment [2,3]. Amstutz and Maki using the trochanteric approach for THAs in the late 70 's found that post-operative abductor insufficiency was associated with pre-operative separation gaps $>2 \mathrm{~cm}$ [69]. In a recent study on 46 RHA's, Caviglia et al. drew the same conclusion indicating significantly worst hip abduction when GTT trochanteric displacement was $>2.5 \mathrm{~cm}$. This finding was independent of the tear type between partial and fullthickness lesions [2].

Makridis et al. in a relative large patient cohort (70 hips) reported that muscle atrophy and not FD had a negative impact on functional outcomes $(P=0.05)$ after open doublerow GTT repair [5]. However, the majority of the patients included were healthy individuals with no history of THA, trauma, or any systemic inflammatory disease. $94 \%$ of these cases had partial lesions of the anterior portion of the Gmed and $20 \%(n=14)$ a FD $\geq 2^{\circ}$. In $60 \%$ of their cases there was 
Table 3 Demographics, findings and outcomes in relation to fatty degeneration of the muscle of gluteus medius et minimus according to Goutallier-Fuchs Classification divided in $<2^{\circ}$ and $\geq 2^{\circ}$ with reports of its significant differences $(P$ values)

\begin{tabular}{|c|c|c|c|}
\hline GFC & $<2^{\circ}$ & $\geq 2^{\circ}$ & $\begin{array}{l}<2^{\circ} \text { vs. } \geq 2^{\circ} \\
P \text { values }\end{array}$ \\
\hline $\mathrm{Nr}$ & $22(57.9 \%)$ & $16(42.1 \%)$ & 0.33 \\
\hline Age & $63 \pm 9.4$ & $70 \pm 9.2$ & $\mathbf{0 . 0 3}$ \\
\hline Gender (females) & $18(81.8 \%)$ & $11(68.8 \%)$ & 0.38 \\
\hline BMI & $27.81 \pm 4.7$ & $29 \pm 6.9$ & 0.56 \\
\hline Etiology & $\begin{array}{l}18(81.8 \%) \text { spontaneous } \\
3(13.6 \%) \text { posttraumatic } \\
1(4.5 \%) \text { prior THA }\end{array}$ & $\begin{array}{l}4(25 \%) \text { spontaneous } \\
2(12.5 \%) \text { posttraumatic } \\
10(62.5 \%) \text { prior THA }\end{array}$ & $<0.001$ \\
\hline Lateral THA approaches & $1 / 1(100 \%) \mathrm{LA}$ & $6 / 7(85.7 \%) \mathrm{LA}$ & 0.02 \\
\hline Prior RHA (nr.) & None & $\begin{array}{l}2 / 10(20 \%) \geq 3 \text { RHA } \\
1 / 10(10 \%)<3 \text { RHA }\end{array}$ & \\
\hline Injured tendons & $\begin{array}{l}52.4 \% \text { Gmed } \\
14.3 \% \text { Gmin } \\
28.6 \% \text { Gmed \& Gmin }\end{array}$ & $\begin{array}{l}37.5 \% \text { Gmed } \\
0 \% \text { Gmin } \\
62.5 \% \text { Gmed \& Gmin }\end{array}$ & 0.08 \\
\hline Tear type Gmed & $\begin{array}{l}38 \% \mathrm{PT} \\
42.9 \% \mathrm{FT} \\
19 \% \text { isolated Gmin PT }\end{array}$ & $\begin{array}{l}31.3 \% \mathrm{PT} \\
68.8 \% \mathrm{FT}\end{array}$ & $\mathbf{0 . 0 3}$ \\
\hline Tear size in $\mathrm{mm}$ & $13.4 \pm 8.1$ & $23.3 \pm 11.7$ & 0.02 \\
\hline Retraction Gmed in mm & $3.2 \pm 8.4$ & $19.4 \pm 19.3$ & 0.02 \\
\hline Muscle atrophy $(\geq 25 \%)$ & $53 \%$ & $96.4 \%$ & 0.002 \\
\hline Bursitis & $1.14 \pm 0.8$ & $2.1 \pm 1.1$ & 0.01 \\
\hline Treatment & $\begin{array}{l}14(63.6 \%) \text { OGR: } \\
13(59.1 \%) \text { pPOGR } \\
1(4.5 \%) \text { rOGR } \\
8(36.4 \%) \text { EGR }\end{array}$ & $\begin{array}{l}15(93.8 \%) \text { OGR: } \\
5(31.3 \%) \text { pOGR } \\
10(62.5 \%) \text { rOGR } \\
1(6.3 \%) \mathrm{EGR}\end{array}$ & $<0.001$ \\
\hline Nr. of anchors & $41 / 22($ mean $1.86 \pm 0.8)$ & $45 / 16($ mean $2.81 \pm 1.1)$ & 0.01 \\
\hline Abduction av. Improvement & $+0.47 \pm 0.8 / 5$ & $+0.5 \pm 0.5 / 5$ & 0.91 \\
\hline Limp av. improvement & $-1.2 \pm 1 / 3$ & $-0.2 \pm 1.4 / 3$ & 0.05 \\
\hline Analgesics av. reduction & $-27 / 33(-81.8 \%)$ & $-23.5 / 27(-87 \%)$ & 0.31 \\
\hline Opioid av. reduction & $-8 / 10(-80 \%)$ & $-3 / 4(-75 \%)$ & 0.35 \\
\hline VAS av. improvement & $-4.6 \pm 2.6 / 10$ & $-3.6 \pm 2.9 / 10$ & 0.32 \\
\hline HOOS Jr & $75.6 \pm 15.6 / 100$ & $69.7 \pm 25.4 / 100$ & 0.44 \\
\hline HHS Section 1 (pain \& function) & $71.7 \pm 13.9 / 91$ & $58.2 \pm 21.7 / 91$ & 0.04 \\
\hline Complications & None $(0 \%)$ & 6 after ROR (37.5\%) & 0.02 \\
\hline
\end{tabular}

Significant values are highlighted in bold

GFC Goutallier-Fuchs Classification, BMI Body-Mass-Index, THA total hip arthroplasty, LA lateral approach, $R H A$ revision hip arthroplasty, Gmed gluteus medius, Gmin gluteus minimus, $P T$ partial tear, $F T$ full-thickness tear, $O G R$ open gluteal repair, $p O G R$ primary open gluteal repair, $r O G R$ revision open gluteal repair (revision total hip arthroplasty with open repair), EGR endoscopic gluteal repair neither FD nor MA evidenced. In our cohort, $\mathrm{FD} \geq 2^{\circ}$ was found in $42.1 \%$ and $\mathrm{MA}$ in $64 \%$, while cases with $\mathrm{FD} \geq 2^{\circ}$ were associated with MA in $96.4 \%$ (Tables 3 and 4).

Based on known similarities between GTTs and rotator cuff tears (RCT) [70] and the available data originating from the shoulder surgery literature, duration of symptoms [71] and age of the patient [72] seem to be associated with increased fatty degeneration of the RCT muscles, whereas, inactivity and nerve injuries lead to muscle atrophy [73].

Total hip arthroplasty (THA) is considered one of the most successful and effective orthopedic procedures. However, $6 \%$ of the patients remain unsatisfied due to persistent pain after surgery $[74,75]$. Limited evidence exists concerning the exact etiology of pain in this critical patient group. The surgical technique chosen to perform a THA may play an essential role in pain generation if it leads to damage to the abductor tendons. A high incidence of postoperative Trendelenburg sign (27.6\%) and limp (4-20\%) has been described after use of the lateral THA approach [14, 15, 19, 76].

Thus, ongoing lateral hip pain with Trendelenburg gait in a patient with a history of a direct or antero-lateral THA should always raise suspicions of a GTT or failed repair of the partial Gluteus Medius take-down. Spontaneous partial GTTs are most commonly found on the anterior portion of the Gmed due to its thinner anterolateral layer [77]. 
Table 4 Demographics, findings and outcomes in relation to atrophy of the abductor muscle with reports of significant differences $(P$ values $)$

\begin{tabular}{|c|c|c|c|}
\hline Atrophy of abductor muscles ( $\geq 25 \%$ ) & No & Yes & $\begin{array}{l}<25 \% \text { vs. } \geq 25 \% \\
P \text { values }\end{array}$ \\
\hline Cases (\%) & $36 \%$ & $64 \%$ & \\
\hline Age & $61.9 \pm 9.2$ & $68 \pm 9.6$ & 0.12 \\
\hline Gender (females) & $7(70 \%)$ & $15(83.3 \%)$ & 0.46 \\
\hline BMI & $28.29 \pm 4.7$ & $28.28 \pm 6.8$ & 1.00 \\
\hline ASA & $\begin{array}{l}0(0 \%) \mathrm{I}^{\circ} \\
10(100 \%) \mathrm{II}^{\circ} \\
0(0 \%) \mathrm{III}^{\circ}\end{array}$ & $\begin{array}{l}2(11.1 \%) \mathrm{I}^{\circ} \\
11(61.1 \%) \mathrm{II}^{\circ} \\
5(27.8 \%) \mathrm{III}^{\circ}\end{array}$ & 0.27 \\
\hline Etiology & $\begin{array}{l}8(80 \%) \text { spontaneous } \\
1(10 \%) \text { posttraumatic } \\
1(10 \%) \text { prior THA }\end{array}$ & $\begin{array}{l}7(38.9 \%) \text { spontaneous } \\
2(11.1 \%) \text { posttraumatic } \\
9(50 \%) \text { prior THA }\end{array}$ & 0.02 \\
\hline Lateral THA approaches & $1 / 1 \mathrm{LA}$ & 6/9 LA & 0.14 \\
\hline Prior RHA (nr.) & None & $\begin{array}{l}2 / 9(22.2 \%) \geq 3 \text { RHA } \\
1 / 9(11.1 \%)<3 \text { RHA }\end{array}$ & 0.10 \\
\hline Injured tendons & $\begin{array}{l}50 \% \text { Gmed } \\
20 \% \text { Gmin } \\
30 \% \text { Gmed \& Gmin }\end{array}$ & $\begin{array}{l}50 \% \text { Gmed } \\
0 \% \text { Gmin } \\
50 \% \text { Gmed \& Gmin }\end{array}$ & 0.60 \\
\hline Tear type Gmed & $\begin{array}{l}50 \% \mathrm{PT} \\
30 \% \text { FT }\end{array}$ & $\begin{array}{l}33.3 \% \mathrm{PT} \\
66.7 \% \mathrm{FT}\end{array}$ & 0.05 \\
\hline Tear size in $\mathrm{mm}$ & $13.7 \pm 8.2$ & $20 \pm 1.3$ & 0.17 \\
\hline Retraction Gmed in $\mathrm{mm}$ & $0 \pm 0$ & $15.3 \pm 1.9$ & 0.01 \\
\hline GFC & $1.48 \pm 0.9$ & $2.6 \pm 0.8$ & $\leq \mathbf{0 . 0 0}$ \\
\hline Bursitis & $0.8 \pm 0.6$ & $2.0 \pm 1.1$ & $\leq \mathbf{0 . 0 0}$ \\
\hline Treatment & $\begin{array}{l}4(40 \%) \text { OGR: } \\
3(30 \%) \text { pOGR } \\
1(10 \%) \text { rOGR } \\
6(60 \%) \text { EGR }\end{array}$ & $\begin{array}{l}16(88.9 \%) \text { OGR: } \\
7(38.9 \%) \text { pOGR } \\
9(50 \%) \text { rOGR } \\
2(11.1 \%) \text { EGR }\end{array}$ & 0.02 \\
\hline Nr. of anchors & $22 / 10($ mean $2.2 \pm 0.9)$ & $45 / 18($ mean $2.5 \pm 1.2)$ & 0.46 \\
\hline $\begin{array}{l}\text { Abduction } \\
\text { av. improvement }\end{array}$ & $+0.22 \pm 0.4 / 5$ & $+0.61 \pm 0.5 / 5$ & 0.09 \\
\hline $\begin{array}{l}\text { Limp } \\
\text { av. improvement }\end{array}$ & $-0.9 \pm 1.2 / 3$ & $-0.4 \pm 1.5 / 3$ & 0.38 \\
\hline $\begin{array}{l}\text { Analgesics } \\
\text { av. reduction }\end{array}$ & $-12 / 14(-85.7 \%)$ & $-28 / 31(-90.3 \%)$ & 0.19 \\
\hline $\begin{array}{l}\text { Opioid } \\
\text { av. reduction }\end{array}$ & $-4 / 5(-80 \%)$ & $-4 / 5(-80 \%)$ & 0.40 \\
\hline $\begin{array}{l}\text { VAS } \\
\text { av. improvement }\end{array}$ & $-3.9 \pm 2.0 / 10$ & $-3.8 \pm 2.6 / 10$ & 0.97 \\
\hline HOOS Jr & $72.1 \pm 17.36 / 100$ & $75.6 \pm 15.6 / 100$ & 0.71 \\
\hline HHS Section1 (pain \& function) & $72.88 \pm 14.3 / 91$ & $63.17 \pm 21.12 / 91$ & 0.19 \\
\hline Complications & $1(10 \%)$ after rOGR & $4(22 \%)$ all after rOGR & 0.89 \\
\hline
\end{tabular}

Significant values are highlighted in bold

The limitations of this work include the retrospective nature of the study and thus, the potential recall bias for some subjective measures of the PROMs that were collected and the resulting small sample size of the subgroups tested here, that might have an influence on the power of the results.

However, this is one of the largest descriptive studies that analyzes the impact of some clinically relevant structural properties of GTTs on the mid-term outcomes after surgical treatment. Our thorough MRI analysis of the GTTs by specialized musculoskeletal radiologist provides a clear and well-established methodology for classifying and reporting results from GTT repairs. Lastly, the majority of the repairs described in our study were performed on "massive" GTTs and outlines the results that can be expected with these patients. We hope that the current study provides important information that could guide physicians to be more aware of the potential benefits of 
GTT repairs and their early referral for surgical intervention before fatty atrophy sets in.

\section{Conclusion}

We report overall excellent results in a large series of GTT repairs and a classification system to predict clinical outcomes from pre-operative imaging. While fatty degeneration can negatively impact functional outcomes, pain relief is reliably achieved. Tear morphology and muscle atrophy did not correlate PROMs in our cohort. Patients should be counseled to expect a residual limp after surgery if they have $\mathrm{GFC} \geq 2^{\circ}$ on MRI.

Acknowledgments We wish to thank the support staff and clinical research coordinators in the Department of Orthopedics at the University of California, San Francisco for their tireless support.

Funding Open Access funding enabled and organized by Projekt DEAL. There is no funding source.

\section{Compliance with ethical standards}

Conflict of interest SAB: Stryker, Johnston and Johnston, Zimmer Biomet, InSilicoTrials.com, Journal of Arthroplasty, Arthroplasty Today, Sira Medical.com. TV: Depuy, Hyalex. ALZ: Stryker.

Ethical approval The study was approved by the appropriate institutional research ethics committee of the University of California San Francisco-Human Research Protection Program (UCSF-HRPP) and was performed in accordance with the ethical standards as laid down in the 1964 Declaration of Helsinki and its later amendments or comparable ethical standards.

Informed consent Informed consent was obtained from all individual participants included in the study.

Open Access This article is licensed under a Creative Commons Attribution 4.0 International License, which permits use, sharing, adaptation, distribution and reproduction in any medium or format, as long as you give appropriate credit to the original author(s) and the source, provide a link to the Creative Commons licence, and indicate if changes were made. The images or other third party material in this article are included in the article's Creative Commons licence, unless indicated otherwise in a credit line to the material. If material is not included in the article's Creative Commons licence and your intended use is not permitted by statutory regulation or exceeds the permitted use, you will need to obtain permission directly from the copyright holder. To view a copy of this licence, visit http://creativecommons.org/licenses/by/4.0/.

\section{References}

1. Cormier G, Berthelot J-M, Maugars Y (2006) Gluteus tendon rupture is underrecognized by French orthopedic surgeons: results of a mail survey. Jt Bone Spine 73:411-413. https://doi. org/10.1016/J.JBSPIN.2006.01.021
2. Caviglia H, Cambiaggi G, Vattani $\mathrm{N}$ et al (2016) Lesion of the hip abductor mechanism. SICOT-J 2:29. https://doi.org/10.1051/sicot $\mathrm{j} / 2016020$

3. Harrasser N, Banke I, Prodinger P et al (2017) "Gluteale Insuuzienz": Was dahinter steckt und wie man helfen kann. Orthopädie \& Rheuma 20:23-26

4. Pfirrmann CWA, Notzli HP, Dora C et al (2005) Abductor tendons and muscles assessed at MR imaging after total hip arthroplasty in asymptomatic and symptomatic patients. Radiology. https://doi. org/10.1148/radiol.2353040403

5. Makridis KG, Lequesne M, Bard H, Djian P (2014) Clinical and MRI results in 67 patients operated for gluteus medius and minimus tendon tears with a median follow-up of 4.6 years. Orthop Traumatol Surg Res 100:849-853. https://doi.org/10.1016/j. otsr.2014.08.004

6. Thaunat M, Clowez G, Desseaux A et al (2018) Influence of muscle fatty degeneration on functional outcomes after endoscopic gluteus medius repair. Arthroscopy 34:1816-1824. https://doi. org/10.1016/j.arthro.2018.01.005

7. Engelken F, Wassilew GI, Köhlitz T et al (2014) Assessment of fatty degeneration of the gluteal muscles in patients with THA using MRI: reliability and accuracy of the goutallier and quartile classification systems. J Arthroplasty 29:149-153. https://doi. org/10.1016/j.arth.2013.04.045

8. Hendry J, Biant LC, Breusch SJ (2012) Abductor mechanism tears in primary total hip arthroplasty. Arch Orthop Trauma Surg 132:1619-1623. https://doi.org/10.1007/s00402-012-1573-9

9. LaPorte C, Vasaris M, Gossett L et al (2018) Gluteus medius tears of the hip: a comprehensive approach. Phys Sportsmed. https:// doi.org/10.1080/00913847.2018.1527172

10. Iorio R, Healy WL, Warren PD, Appleby D (2006) Lateral trochanteric pain following primary total hip arthroplasty. J Arthroplasty 21:233-236. https://doi.org/10.1016/j.arth.2005.03.041

11. Dishkin-Paset J, Salata M, Gross C et al (2012) A biomechanical comparison of repair techniques for complete gluteus medius tears. Arthroscopy 28:1410-1416. https://doi.org/10.1016/j.arthr o.2012.03.002

12. Putnam JG, Chhabra A, Castañeda $P$ et al (2018) Does greater trochanter decortication affect suture anchor pullout strength in abductor tendon repairs? A biomechanical study. Am J Sports Med 46:1668-1673. https://doi.org/10.1177/0363546518759033

13. Von Roth P, Abdel MP, Wauer F et al (2014) Significant muscle damage after multiple revision total hip replacements through the direct lateral approach. Bone Jt J 96:1618-1622. https://doi. org/10.1302/0301-620X.96B12

14. Masonis J, Bourne R (2002) Surgical approach, abductor function, and total hip arthroplasty dislocation. Clin Orthop Relat Res 405:46-53

15. Baker AS, Bitounis VC (1989) Abductor function after total hip replacement. An electromyographic and clinical review. J Bone Jt Surg Br 71:47-50

16. Khan T, Knowles D (2007) Damage to the superior gluteal nerve during the direct lateral approach to the hip: a cadaveric study. J Arthroplasty 22:1198-1200. https://doi.org/10.1016/J. ARTH.2006.11.013

17. Fisher DA, Almand JD, Watts MR (2007) Operative repair of bilateral spontaneous gluteus medius and minimus tendon ruptures. J Bone Jt Surg 89:1103-1107. https://doi.org/10.2106/ JBJS.F.01201

18. Bajwa AS, Middleton F, Campbell DG et al (2011) Gluteal tendon reconstruction in association with hip arthroplasty. HIP Int. https ://doi.org/10.5301/HIP.2011.8414

19. Svensson O, Sköld S, Blomgren G (1990) Integrity of the gluteus medius after the transgluteal approach in total hip arthroplasty. $\mathrm{J}$ Arthroplasty 5:57-60 
20. Fink B (2012) Rekonstruktion chronischer Glutaeus-mediusRupturen unter Verwendung eines nichtresorbierbaren Patchs. Oper Orthop Traumatol 24:23-31. https://doi.org/10.1007/s0006 4-011-0073-3

21. Fink B, Braun L (2018) Treatment of extensive gluteus muscle tears with transosseous fixation and a nonresorbable collagen patch. J Arthroplasty 33:555-559. https://doi.org/10.1016/j. arth.2017.08.045

22. Rao BM, Kamal TT, Vafaye J, Taylor L (2012) Surgical repair of hip abductors. A new technique using Graft Jacket allograft acellular human dermal matrix. Int Orthop 36:2049-2053. https ://doi.org/10.1007/s00264-012-1630-6

23. Saltzman B, Ukwuani G, Makhni E et al (2018) The effect of platelet-rich fibrin matrix at the time of gluteus medius repair: a retrospective comparative study. Arthroscopy 34:832-841. https ://doi.org/10.1016/j.arthro.2017.09.032

24. Fehm MN, Huddleston JI, Burke DW et al (2010) Repair of a deficient abductor mechanism with achilles tendon allograft after total hip replacement. J Bone Jt Surg Ser A. https://doi. org/10.2106/JBJS.I.01011

25. Whiteside LA (2012) Surgical technique: transfer of the anterior portion of the gluteus maximus muscle for abductor deficiency of the hip. Clin Orthop Relat Res 470:503-510. https://doi. org/10.1007/s11999-011-1975-y

26. Wang K, Cole S, White DC, Armstrong MS (2014) Vastus lateralis transfer for severe hip abductor deficiency: a salvage procedure. HIP Int. https://doi.org/10.5301/hipint.5000099

27. Drexler M, Abolghasemian M, Kuzyk PR et al (2015) Reconstruction of chronic abductor deficiency after revision hip arthroplasty using an extensor mechanism allograft. Bone Jt J 97-B:1050-1055. https://doi. org/10.1302/0301-620X.97B8.35641

28. Beck M, Leunig M, Ellis T, Ganz R (2004) Advancement of the vastus lateralis muscle for the treatment of hip abductor discontinuity. J Arthroplasty 19:476-480. https://doi.org/10.1016/j. arth.2003.11.014

29. Betz M, Zingg PO, Peirrmann CW, Dora C (2012) Advancement of the vastus lateralis muscle for irreparable hip abductor tears: clinical and morphological results. Acta Orthop Belg 78:337-343

30. Kohl S, Evangelopoulos DS, Siebenrock KA, Beck M (2012) Hip abductor defect repair by means of a vastus lateralis muscle shift. J Arthroplasty 27:625-629. https://doi.org/10.1016/j. arth.2011.06.034

31. Drexler M, Dwyer T, Kosashvili Y et al (2014) Acetabular cup revision combined with tensor facia lata reconstruction for management of massive abductor avulsion after failed total hip arthroplasty. J Arthroplasty 29:1052-1057. https://doi. org/10.1016/j.arth.2013.09.056

32. Whiteside LA (2014) Surgical technique: Gluteus maximus and tensor fascia lata transfer for primary deficiency of the abductors of the hip. Clin Orthop Relat Res 472:645-653. https://doi. org/10.1007/s11999-013-3161-x

33. Whiteside LA, Nayfeh T, Katerberg BJ (2006) Gluteus maximus flap transfer for greater trochanter reconstruction in revision THA. Clin Orthop Relat Res 453:203-210. https://doi. org/10.1097/01.blo.0000246538.75123.db

34. Walsh MJ, Walton JR, Walsh NA (2011) Surgical repair of the gluteal tendons: a report of 72 cases. J Arthroplasty 26:15141519. https://doi.org/10.1016/j.arth.2011.03.004

35. Miozzari HH, Dora C, Clark JM, Nötzli HP (2010) Late repair of abductor avulsion after the transgluteal approach for hip arthroplasty. J Arthroplasty 25:450-457.e1. https://doi. org/10.1016/j.arth.2008.12.010
36. Davies H, Zhaeentan S, Tavakkolizadeh A, Janes G (2009) Surgical repair of chronic tears of the hip abductor mechanism. Hip Int 19:372-376

37. Lequesne M, Djian P, Vuillemin V, Mathieu P (2008) Prospective study of refractory greater trochanter pain syndrome. MRI findings of gluteal tendon tears seen at surgery. Clinical and MRI results of tendon repair. Jt Bone Spine 75:458-464. https ://doi.org/10.1016/j.jbspin.2007.12.004

38. Lübbeke A, Kampfen S, Stern R, Hoffmeyer P (2008) Results of surgical repair of abductor avulsion after primary total hip arthroplasty. J Arthroplasty 23:694-698. https://doi. org/10.1016/j.arth.2007.08.018

39. Perka C, Schütz M, Schröder JH et al (2018) Offene refixation von gluteus medius und minimus in double-row-technikopen repair of gluteus medius and minimus tendons tears with double-row technique. Orthopade 47:238-245. https://doi. org/10.1007/s00132-017-3524-1

40. Bucher TA, Darcy P, Ebert JR et al (2014) Gluteal tendon repair augmented with a synthetic ligament: surgical technique and a case series. HIP Int 24:187-193. https://doi.org/10.5301/hipin t.5000093

41. Davies JF, Stiehl JB, Davies JA, Geiger PB (2013) Surgical treatment of hip abductor tendon tears. J Bone Jt Surg Am 95:1420-1425. https://doi.org/10.2106/JBJS.L.00709

42. Stanton MC, Maloney MD, Dehaven KE, Giordano BD (2012) Acute traumatic tear of gluteus medius and minimus tendons in a patient without antecedant peritrochanteric hip pain. Geriatr Orthop Surg Rehabil 3:84-88. https://doi.org/10.1177/21514 58512441795

43. Schuh A, Zeiler G (2003) Die Ruptur der Sehne des Musculus glutaeus medius. Zentralbl Chir 128:139-143. https://doi. org/10.1055/s-2003-37768

44. Kagan A (1999) Rotator cuff tears of the hip. Clin Orthop Relat Res. https://doi.org/10.1097/00003086-199911000-00016

45. Rajkumar S, Singer GC, Jones JR (2011) Results following repair of gluteus medius defects following total hip arthroplasty. Hip Int 21:293-298. https://doi.org/10.5301/HIP.2011.8400

46. Chandrasekaran S, Gui C, Hutchinson MR et al (2015) Outcomes of endoscopic gluteus medius repair. J Bone Jt Surg Am 97:1340 1347. https://doi.org/10.2106/JBJS.N.01229

47. Domb BG, Carreira DS (2013) Endoscopic repair of full-thickness gluteus medius tears. Arthrosc Tech 2:e77-e81. https://doi. org/10.1016/j.eats.2012.11.005

48. McCormick F, Alpaugh K, Nwachukwu B et al (2013) Endoscopic repair of full-thickness abductor tendon tears: surgical technique and outcome at minimum of 1-year follow-up. Arthroscopy 29:1941-1947. https://doi.org/10.1016/j.arthro.2013.08.024

49. Perets I, Mansor Y, Yuen L et al (2017) Endoscopic gluteus medius repair with concomitant arthroscopy for labral tears: a case series with minimum 5-year outcomes. Arthroscopy 33:21592167. https://doi.org/10.1016/j.arthro.2017.06.032

50. Thaunat M, Chatellard R, Noël E et al (2013) Endoscopic repair of partial-thickness undersurface tears of the gluteus medius tendon. Orthop Traumatol Surg Res 99:853-857. https://doi.org/10.1016/j. otsr.2013.06.005

51. Voos JE, Shindle MK, Pruett A et al (2009) Endoscopic repair of gluteus medius tendon tears of the hip. Am J Sports Med 37:743747. https://doi.org/10.1177/0363546508328412

52. Yanke AB, Hart MA, McCormick F, Nho SJ (2013) Endoscopic repair of a gluteus medius tear at the musculotendinous junction. Arthrosc Tech 2:e69-72. https://doi.org/10.1016/j. eats.2012.11.004

53. Hartigan D, Perets I, Ho S et al (2018) Endoscopic repair of partial-thickness undersurface tears of the abductor tendon: clinical outcomes with minimum 2-year follow-up. Arthroscopy 34:11931199. https://doi.org/10.1016/j.arthro.2017.10.022 
54. Maslaris A, Vail TP, Zhang AL et al (2020) Equivalent mid-term results of open vs endoscopic gluteal tendon tear repair using suture anchors in forty-five patients. J Arthroplasty. https://doi. org/10.1016/j.arth.2020.03.013

55. Fuchs B, Weishaupt D, Zanetti M et al (1999) Fatty degeneration of the muscles of the rotator cuff: assessment by computed tomography versus magnetic resonance imaging. J Shoulder Elb Surg 8:599-605. https://doi.org/10.1016/S1058-2746(99)90097-6

56. Somerson JS, Hsu JE, Gorbaty JD, Gee AO (1999) IN BRIEF classifications in brief: goutallier classification of fatty infiltration of the rotator cuff musculature. Clin Orthop Relat Res. https://doi. org/10.1007/s11999-015-4630-1

57. Gottschalk F, Leveau B (1989) The functional anatomy of tensor fasciae latae and gluteus medius and minimus. J Anat 166:179-189

58. Cvitanic O, Henzie G, Skezas N et al (2004) MRI diagnosis of tears of the hip abductor tendons (gluteus medius and gluteus minimus). AJR Am J Roentgenol 182:137-143. https://doi. org/10.2214/ajr.182.1.1820137

59. Chi AS, Long SS, Zoga AC et al (2015) Prevalence and pattern of gluteus medius and minimus tendon pathology and muscle atrophy in older individuals using MRI. Skeletal Radiol 44:17271733. https://doi.org/10.1007/s00256-015-2220-7

60. Klässbo M, Larsson E, Mannevik E (2003) Hip disability and osteoarthritis outcome score. An extension of the Western Ontario and McMaster Universities Osteoarthritis Index. Scand J Rheumatol 32:46-51

61. Harris WH (1969) Traumatic arthritis of the hip after dislocation and acetabular fractures: treatment by mold arthroplasty. An endresult study using a new method of result evaluation. J Bone $\mathrm{Jt}$ Surg Am 51:737-755

62. Hermans G, Clerckx B, Vanhullebusch T et al (2012) Interobserver agreement of medical research council sum-score and handgrip strength in the intensive care unit. Muscle Nerve 45:1825. https://doi.org/10.1002/mus.22219

63. Ebert JR, Bucher TA, Ball SV, Janes GC (2015) A review of surgical repair methods and patient outcomes for gluteal tendon tears. HIP Int 25:15-23. https://doi.org/10.5301/hipint.5000183

64. Domb BG, Botser I, Giordano BD (2013) Outcomes of endoscopic gluteus medius repair with minimum 2-year follow-up. Am J Sports Med 41:988-997. https://doi.org/10.1177/0363546513 481575

65. Ozaki T, Kaneko S, Kunisada T et al (1999) Reconstruction of the hip abductors after resection of the proximal femur. Int Orthop 23:182-183. https://doi.org/10.1007/S002640050342
66. Suppauksorn S, Nwachukwu BU, Beck EC et al (2019) Superior gluteal reconstruction for severe hip abductor deficiency. Arthrosc Tech 8:e1255-e1261. https://doi.org/10.1016/j.eats.2019.06.016

67. Kenny P, O'Brien CP, Synnott K, Walsh MG (1999) Damage to the superior gluteal nerve after two different approaches to the hip. J Bone Jt Surg Br 81:979-981

68. Ramesh M, O'Byrne J, McCarthy N et al (1996) Damage to the superior gluteal nerve after the hardinge approach to the hip. $\mathrm{J}$ Bone Jt Surg Br. https://doi.org/10.1302/0301-620X78B6.1289

69. Amstutz H, Maki S (1978) Complications of trochanteric osteotomy in total hip replacement. J Bone Jt Surg Am 60:214-216

70. Bunker T, Esler C, Leach W (1997) Rotator-cuff tear of the hip. J Bone Jt Surg Br 79:618-620. https://doi. org/10.1302/0301-620X.79B4.7033

71. Goutallier D, Postel J, Bernageau J et al (1994) Fatty muscle degeneration in cuff ruptures. Pre- and postoperative evaluation by CT scan. Clin Orthop Relat Res 304:78-83. https://doi. org/10.1097/00003086-199407000-00014

72. Barry JJ, Lansdown DA, Cheung S et al (2013) The relationship between tear severity, fatty infiltration, and muscle atrophy in the supraspinatus. J Shoulder Elb Surg 22:18-25. https://doi. org/10.1016/j.jse.2011.12.014

73. Kuzel BR, Grindel S, Papandrea R, Ziegler D (2013) Fatty infiltration and rotator cuff atrophy. J Am Acad Orthop Surg 21:613-623. https://doi.org/10.5435/JAAOS-21-10-613

74. Wylde V, Hewlett S, Learmonth ID, Dieppe P (2011) Persistent pain after joint replacement: prevalence, sensory qualities, and postoperative determinants. Pain 152:566-572. https://doi. org/10.1016/j.pain.2010.11.023

75. Lanting BA, MacDonald SJ (2013) The painful total hip replacement: diagnosis and deliverance. Bone Jt J 95-B:70-73. https:// doi.org/10.1302/0301-620X.95B11.32948

76. Edmunds CT, Boscainos PJ (2011) Effect of surgical approach for total hip replacement on hip function using Harris Hip scores and Trendelenburg's test. A retrospective analysis. Surg 9:124-129. https://doi.org/10.1016/j.surge.2010.08.014

77. Tsutsumi M, Nimura A, Akita K (2019) The gluteus medius tendon and its insertion sites: an anatomical study with possible implications for gluteus medius tears. J Bone Jt Surg Am 101:177-184. https://doi.org/10.2106/JBJS.18.00602

Publisher's Note Springer Nature remains neutral with regard to jurisdictional claims in published maps and institutional affiliations.

\section{Authors and Affiliations}

\section{Alexander Maslaris ${ }^{1,2,3} \cdot$ Thomas P. Vail $^{1} \cdot$ Alan L. Zhang $^{1} \cdot$ Rina Patel $^{4} \cdot$ Stefano A. Bini ${ }^{1}$}

Thomas P. Vail

Thomas.Vail@ucsf.edu

Alan L. Zhang

Alan.Zhang@ucsf.edu

Rina Patel

Rina.Patel@ucsf.edu

1 Department of Orthopaedic Surgery, University of California, 400 Parnassus Avenue, MU320-W, San Francisco, CA 94143, USA
2 Department of Orthopaedics, Friedrich-Schiller University of Jena, Campus Eisenberg, 07607 Eisenberg, Germany

3 Department of Orthopaedics and Trauma Surgery, Alfried-Krupp Hospital, Campus Rüttenscheid, 45131 Essen, Germany

4 Department of Radiology of Biomedical Imaging, University of California, 400 Parnassus Avenue, MU320-W, San Francisco, CA 94143, USA 